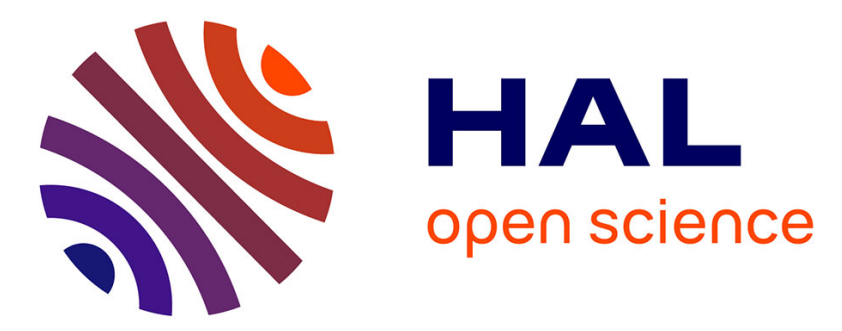

\title{
Numerical Modeling of Human Effect on Indoor Propagation
}

\author{
Zaher Sayegh, Mohamed Latrach, Fumie Costen, Ghaïs El Zein, Gheorghe \\ Zaharia
}

\section{> To cite this version:}

Zaher Sayegh, Mohamed Latrach, Fumie Costen, Ghaïs El Zein, Gheorghe Zaharia. Numerical Modeling of Human Effect on Indoor Propagation. 13th Mediterranean Microwave Symposium (MMS), Sep 2013, Saida, Lebanon. pp.1-4. hal-00873947

\section{HAL Id: hal-00873947 https://hal.science/hal-00873947}

Submitted on 16 Oct 2013

HAL is a multi-disciplinary open access archive for the deposit and dissemination of scientific research documents, whether they are published or not. The documents may come from teaching and research institutions in France or abroad, or from public or private research centers.
L'archive ouverte pluridisciplinaire HAL, est destinée au dépôt et à la diffusion de documents scientifiques de niveau recherche, publiés ou non, émanant des établissements d'enseignement et de recherche français ou étrangers, des laboratoires publics ou privés. 


\title{
Numerical Modeling of Human Effect on Indoor Propagation
}

\author{
Zaher SAYEGH ${ }^{1,3}$, Mohamed LATRACH ${ }^{1}$, Fumie COSTEN $^{2}$, Ghais EL ZEIN ${ }^{3}$, Gheorghe ZAHARIA ${ }^{3}$ \\ ${ }^{1}$ IETR - ESEO, Groupe Radio et Hyperfréquence, 10 Bd Jean Jeanneteau, CS 90717, 49107 Angers Cedex2, France \\ ${ }^{2}$ School of Electric and Electrical Engineering, University of Manchester, U.K. \\ ${ }^{3}$ IETR - INSA de Rennes, 20 Avenue des Buttes de Cö̈smes, CS 70839 F - 35708 Rennes Cedex 7, France \\ Zaher.sayegh@eseo.fr
}

\begin{abstract}
The impact of human body on the wireless communication systems is very required recently in indoor environments. The prediction of accurate and efficient coverage is more and more needed in the presence of various obstacles. This paper will present electromagnetic indoor propagation modeling with integration of human body, taking into account the nature of materials existing in the environment, based on 3DFinite-Difference Time-Domain method. Numerical results obtained by this method are presented.
\end{abstract}

Keywords-indoor propagation modeling; FDTD; prediction; human body

\section{INTRODUCTION}

Planning efficiently the communicating devices becomes essential in indoor environments. The presence of obstacles influences the coverage by their geometrical and material characteristics.

A code developed with FORTRAN and based on the 3D FDTD method allowing to obtain interesting results in agreement with measurements with presence of various obstacles in the environment [1] - [2], has been enhanced to take into account the presence of human body to get more accuracy.

The code provides the electromagnetic fields in time domain for each position of the receiving antenna in the environment, which allows us to calculate the corresponding power through the calculation of the Poynting vector [14].

In this paper we are looking to integrate the human body in the FDTD code and to predict the radiation of omnidirectional monopole antenna $(\lambda / 4)$ at $2.4 \mathrm{GHz}$ placed in typical office environment in presence of various obstacles as presented in Fig. 1.

\section{SCENARIO}

A typical office measuring $34 \lambda \times 27 \lambda \times 24 \lambda$ is used for this study [1] featuring several types of obstacles such a brick enclosure walls, one metal heater, two metal wardrobes, two metal desks, two computers, two screens, four glass windows and one wooden door. We used monopole omnidirectional antennas with the physical size of $\lambda / 4$ and resonate at $2.4 \mathrm{GHz}$.

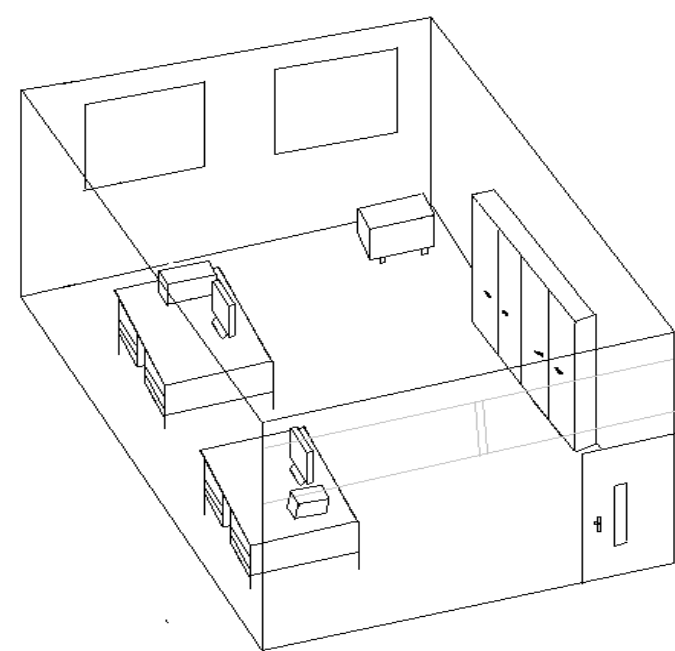

Fig. 1 - Office environment study

\section{INTEGRATION OF HUMAN BODY IN THE FDTD CODE}

The scenario was created by the FDTD code by defining the geometries and the materials of the environment.

The current version of the FDTD code allows us to integrate a human body in the environment (height: $169 \mathrm{~cm}$ as shown in Fig. 2) including the properties of all existing materials inside.

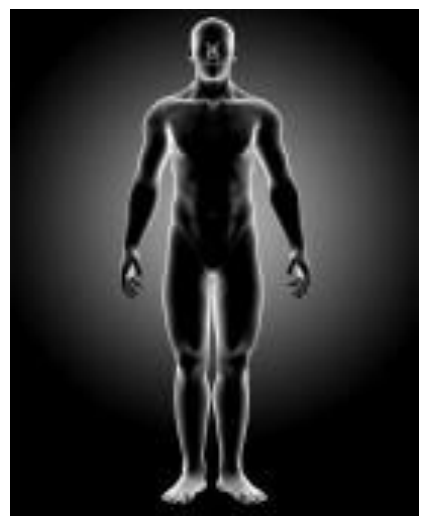

Fig. 2 - Model of human body (height: $169 \mathrm{~cm}$ ) 
We need to specify the coordinates $(x, y)$ of the point where we want it to be placed; this point corresponds to the center of the body. We can also specify the orientation of the body according to the office geometry.

In our study we choose to place the human body in the middle of the office (Fig. 3).

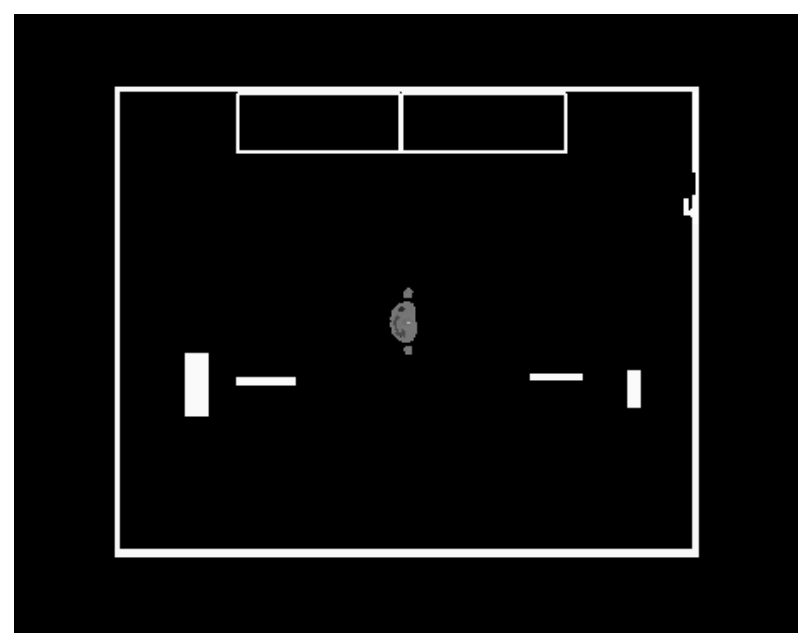

Fig. 3 - Obstacles cut plan at $\mathrm{z}=85 \mathrm{~cm}$

Fig. 3 shows the obstacles existing in the plan $(\mathrm{x}, \mathrm{y})$ at $\mathrm{z}=$ $85 \mathrm{~cm}$. We can see the body in the middle of the office with a part of two hands, the wardrobes, the door, the walls, the computer and the screens.

In our study the frequency is $2.4 \mathrm{GHz}$, we used as source an omnidirectional antenna placed $85 \mathrm{~cm}$ above the floor level.

The spatial step is $\lambda / 10$, or $\lambda$ is the wavelength, chosen to be small to get a perfect continuity of space and time and to minimize the errors introduced by the numerical dispersions. The choice of the spatial step is a compromise between the minimization of inaccuracy and storage space in memory.

The code has a capability to produce the electric field and the magnetic field in time domain at any locations in the FDTD space taking into account the presence of the human body in the middle of the office.

The calculation is done for 2000 time steps or the time step is $2.4 \mathrm{e}-02 \mathrm{~ns}$.

We specify the output points or plan where we need to get the fields values ('txt' files) or we can choose 'PPM' files to see how electromagnetic waves propagate inside the room for each time step (Fig. 4). For this study we defined horizontal output plan as the same level of the source antenna.

Fig. 4 shows how electromagnetic waves propagate inside the office at $\mathrm{z}=85 \mathrm{~cm}$.

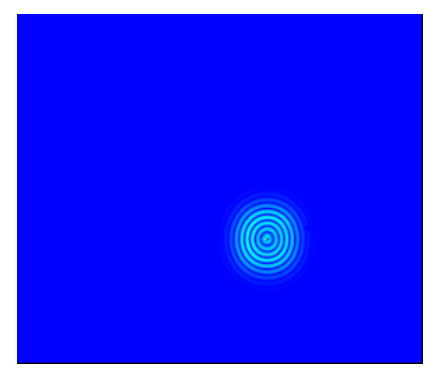

$\mathrm{t}=3 \mathrm{~ns}$

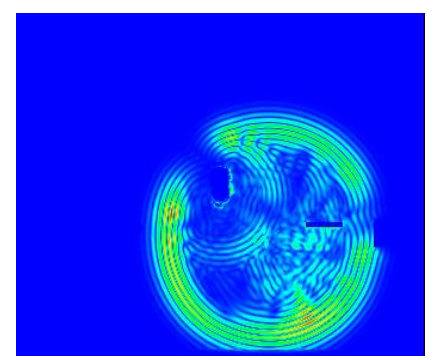

$\mathrm{t}=5.76 \mathrm{~ns}$

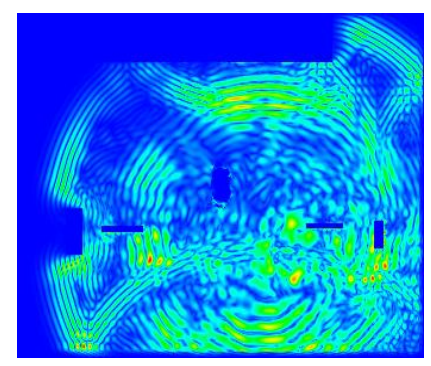

$\mathrm{t}=9.72 \mathrm{~ns}$

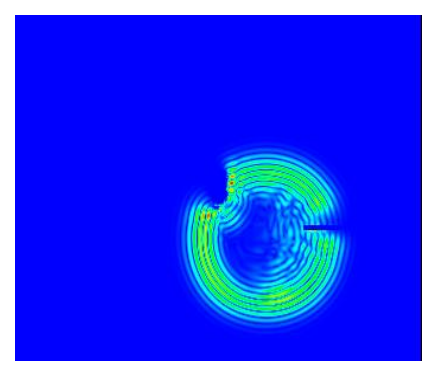

$\mathrm{t}=4.44 \mathrm{~ns}$

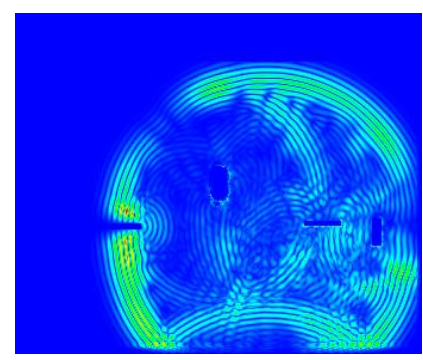

$\mathrm{t}=7.44 \mathrm{~ns}$

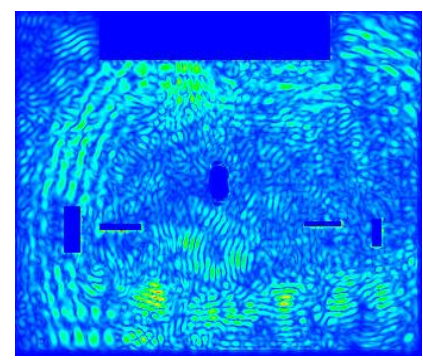

$\mathrm{t}=18.24 \mathrm{~ns}$
Fig. 4 - Electromagnetic waves propagation in presence of human body in time domain

\section{USING MULTIPLE SOURCES}

The code has been developed to taking into account the presence of multiple sources in the environment.

Fig. 5 shows how electromagnetic waves propagate in the office in the presence of multiple sources and the human body in the office, taking into account all the significant physical phenomena influencing the wave's propagation like signal reflection, absorption, penetration and also diffuse scattering. 


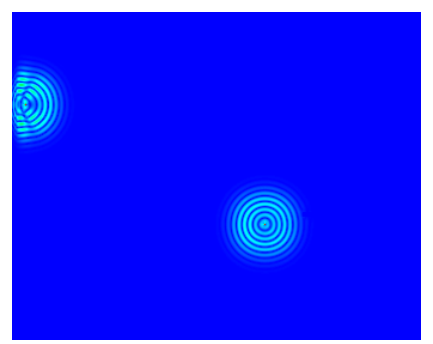

$\mathrm{t}=3 \mathrm{~ns}$

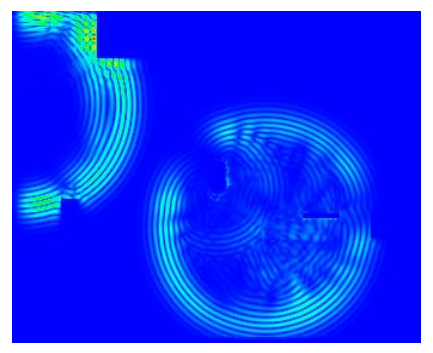

$\mathrm{t}=5.76 \mathrm{~ns}$

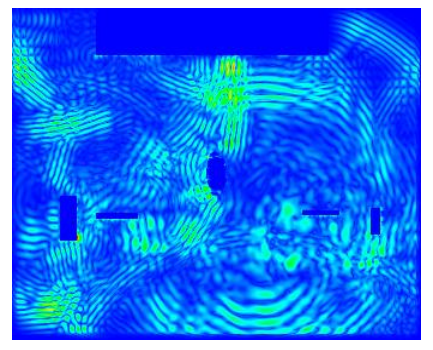

$\mathrm{t}=9.72 \mathrm{~ns}$

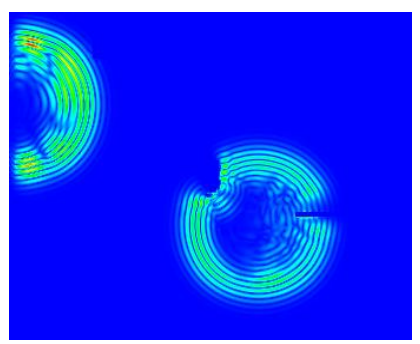

$\mathrm{t}=4.44 \mathrm{~ns}$

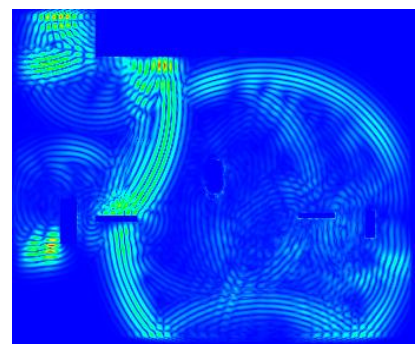

$\mathrm{t}=7.44 \mathrm{~ns}$

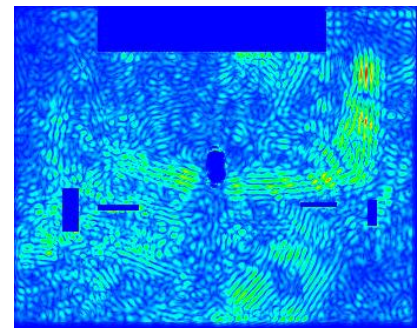

$\mathrm{t}=14.64 \mathrm{~ns}$
Fig. 5 - Electromagnetic waves propagation in presence of multiple sources and human body in time domain

\section{COMPARISON BETWEEN SIMULATIONS IN PRESENCE AND ABSENCE OF HUMAN BODY}

The impact of human body on the antenna radiation in the environment can be seen by comparison between simulations in presence and absence of human body in the office.

The repartition of power loss computed with FDTD code for 143 points separate by $2.5 \lambda$ chosen at the same height of the source is represented in Fig. 6.

Fig. 6 (a) shows the repartition of power loss computed without human body. The influence of wardrobes, heater, computers and screens can be seen by the dark blue areas.

Fig. 6 (b) shows the repartition of power loss computed with presence of human body in the middle of the office. An important influence on the in-room coverage is noticed.

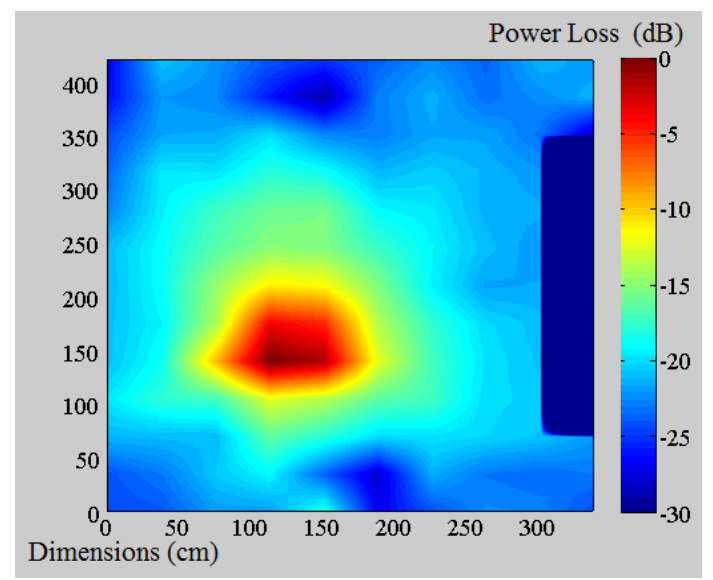

(a)

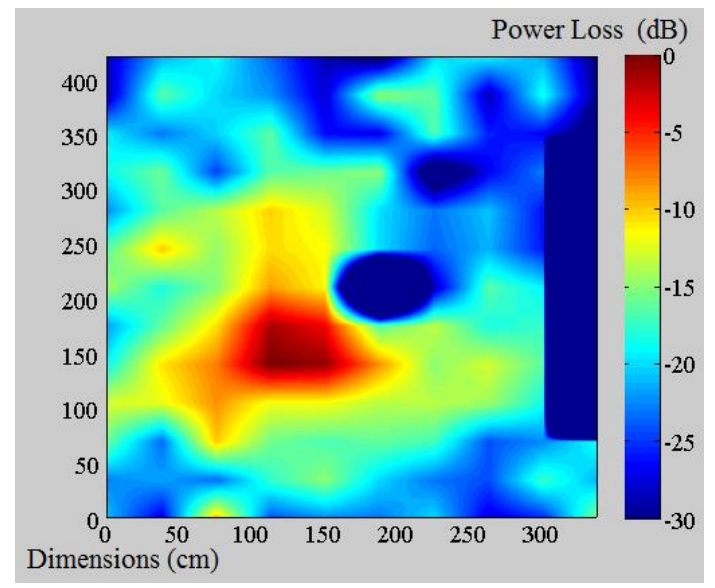

(b)

Fig. 6 - Repartition of Power Loss (dB) obtained by FDTD code:
(a) without human body
(b) with presence of human body

The difference between these simulations is represented in Fig. 7. We can see how the in-room coverage becomes poor in the area between the body and the heater and how it becomes better in the other areas.

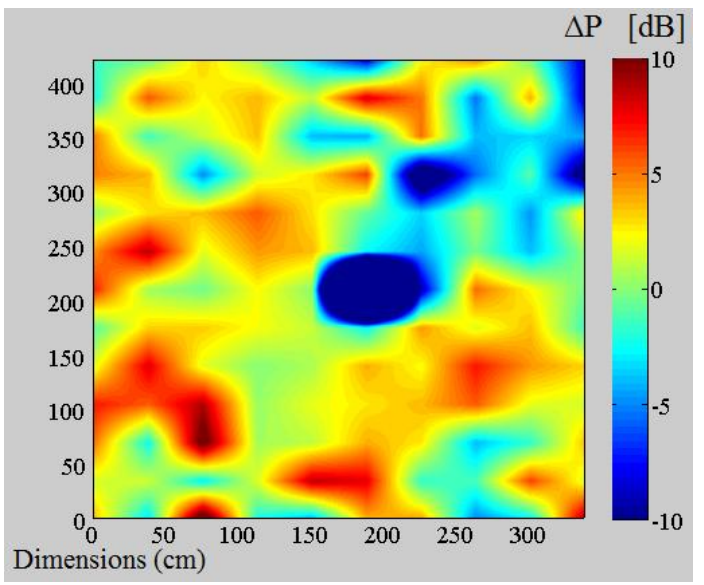

Fig. 7 - Difference of Power Loss (dB) between simulations in presence and absence of human body 


\section{COMPUTATIONAL PERFORMANCE}

The FDTD code was enhanced to use all processors for simulation to reduce the computation time.

For this study, we used one computer which has 8 processors and $32 \mathrm{~GB}$ of RAM. The computation time for each study was about 37 minutes, using 8 processors and $2.25 \mathrm{~GB}$ of RAM. The storage space on the hard disk is about $20 \mathrm{MB}$.

Table I. shows the difference between the performance of computation using one processor and 8 processors.

TABLE I. FDTD CODE PERFORMANCE

\begin{tabular}{|c|c|c|c|}
\hline Method & $\begin{array}{c}\text { Number of } \\
\text { processors }\end{array}$ & Computation time & $\begin{array}{c}\text { Memory } \\
(\text { RAM })\end{array}$ \\
\hline FDTD code & 1 & $9 \mathrm{~h} 11$ & $2.25 \mathrm{~GB}$ \\
\hline FDTD code & 8 & 37 minutes & $2.25 \mathrm{~GB}$ \\
\hline
\end{tabular}

\section{CONCLUSION}

An accurate and efficient electromagnetic indoor propagation modeling based on the 3D FDTD method is developed and presented in this paper. This code takes into account the presence of obstacles, multiple sources and human body in the environment to provide results with accuracy.

Numerical results obtained by the FDTD code are presented. The important influence of human body on the indoor coverage is shown by comparison between the simulations in presence and absence of human body.

The performance of the FDTD code shows a great ability in modeling electromagnetic propagation.

To get more accuracy, we need to compare between numerical results using FDTD code and measurements results. The characteristics of antenna should also be integrated in the FDTD code.

\section{REFERENCES}

[1] Z. Sayegh, M. Latrach, F. Costen, W. Abdouni, G. El Zein, G. Zaharia, "Antenna Radiation in Typical Office Environment: Theoretical Modeling and Measurements», Computer Modeling and Simulation (EMS), 2012 Sixth UKSim/AMSS European Symposium on Mathematical Modelling and Computer Simulation, 14-16 Nov. 2012, pp. 433-438.

[2] Z. Sayegh, M. Latrach, F. Costen, W. Abdouni, G. El Zein, G. Zaharia, «Modélisation de la Propagation Electromagnétique dans un Environnement de Type Bureau à $2.4 \mathrm{GHz}$, Journées Nationales Microondes JNM,Paris, France, 15-16-17 May 2013.

[3] Allen Taflove, Susan C. Hagness, Computational Electrodynamics: The finite-difference time-domain method, Artech House, Norwood, 2005.

[4] Yee K, "Numerical Solution of Initial Boundary Value Problems Involving Maxwell's Equations in Isotropic Media”, IEEE Trans. Ant. Prop., vol. 33, May 1966, pp.302-307.

[5] Taflove A and Brodwin M, "Numerical solution of steady state electromagnetic scattering problems using the time dependent Maxwell's equations", IEEE MTT, vol. 23, no. 1, Aug. 1975, pp. 623630.

[6] D Sheen, S Ali, M Abouzahra, and J Kong, "Application of ThreeDimensional Finite-Difference Method to the Analysis of Planar Microstrip Circuits”, IEEE MTT, vol. 38, pp. 849-57, Jul 1990.

[7] X Zang, J Fang and K Mei, "Calculations of the dispersive characteristics of microstrips by the FDTD method", IEEE MTT, vol. 26, pp. 263-267, Feb. 1988.

[8] Railton $\mathrm{C}$ and McGeehan, "Analysis of microstrip discontinuities using the FDTD method", MWSYM 1989, pp. 1089-1012.

[9] Shibata T, Havashi T and Kimura T, "Analysis of microstrips circuits using three-dimensional full-wave electromagnetic field analysis in the time-domain", IEEE MTT, vol. 36, pp. 1064-1070, Jun. 1988.

[10] Feix N, Lalande M and Jecko B, "Harmonically Characterization of a Microstrip Bend via the FDTD Method", IEE Proceedings, IEEE MTT, vol. 40, no. 5, May 1992, pp. 955-961.

[11] A Taflove, "The Finite-Difference Time-Domain Method for Electromagnetic Scattering and Interaction Problems", IEEE Trans. Electromagnetic Compatibility, vol. EMC-22, pp. 191-202, Aug. 1980.

[12] Railton CJ, Richardson KM, McGeehan JP and Elder KF, "The Prediction of Radiation Levels from Printed Circuit Boards by means of the FDTD Method", IEE International Conference on Computation in Electromagnetics, Savoy Place, London, Nov. 1991.

[13] WJ Buchanan, NK Gupta, "Prediction of Electric Fields from Conductors on a PCB by 3D Finite-Difference Time-Domain Method", IEE's Engineering, Science and Education Journal, Aug. 1995.

[14] P. Neeakanta, T. Kishkan, R. Chaterjee, “Antennas for Information Super Skyways: An Exposition on Outdoor and Indoor Wireless Antennas", Research Studies Press Ltd, pp. 223, $1^{\text {st }}$ edition (December 1, 2002). 